\title{
O projeto pedagógico em escolas municipais: análise da relação entre a autonomia e manutenção e/ou modificação de práticas escolares.
}

Ivanise Monfredini

Centro Universitário Nove de Julho

\section{Resumo}

Neste texto discutimos o projeto pedagógico e a relação com a gestão autônoma da escola. Decorridos cinco anos da aprovação da Lei de Diretrizes e Bases da Educação (LDB 9394/96), que prevê a autonomia pedagógica e a participação da comunidade na gestão escolar, interessou-nos investigar a autonomia como prática social. De que modo a autonomia delegada contribui para que se mantenham e/ou se modifiquem as práticas estabelecidas na escola? Ao mesmo tempo em que o projeto pedagógico normatizado/legalizado impõe sérios controles ao trabalho que se desenvolve na escola, concretizam-se algumas condições para práticas alternativas, que afirmam a autonomia, não como universalidade abstrata, mas concreta, historicamente constituída. A pesquisa foi realizada em 37 escolas da rede municipal de ensino da cidade de São Paulo. Durante os anos de 1999 e 2000 a equipe técnica dessas escolas - diretores, assistentes de diretoria e coordenadores pedagógicos - respondeu a um questionário e participou de quatro encontros cujo objetivo foi refletir sobre a implantação e/ou implementação do projeto pedagógico nas respectivas escolas.

Os dados sugerem a ausência de um referencial público para a construção do horizonte ético indicado pelo projeto pedagógico. A construção e a implementação do projeto pedagógico nas escolas refletem muito mais a busca de soluções imediatas aos graves problemas que afetam o cotidiano escolar. Sugerem ainda que aquilo que se chama de autonomia da escola se constitui na autonomia do grupo de educadores mais atuantes na escola.

\section{Palavras-chave:}

Educação - Política educativa - Projeto político-pedagógico.
Correspondência: Ivanise Monfredini

Centro Universitário Nove de Julho Av. Dr. Adolfo Pinto, $109-9^{\circ}$ andar. 01156-050- São Paulo - Capital e-mail: ivanise@uninove.br 


\section{The pedagogical project in municipal schools: analysis of the relationship between autonomy and the preservation and/or modification of school practices}

Ivanise Monfredini

Nove de Julho University Center

\begin{abstract}
In this text we discuss the pedagogical project and its relationship to the autonomous management of the school. Five years have elapsed since the sanctioning of the LDB 9394/96 (Education Principles and Guidelines Act), which establishes pedagogical autonomy and community participation in the management of school, arising our interest in investigating autonomy as a social practice. How does the autonomy granted contribute to the preservation and/or modification of established practices at school? At the same time that the standardized/ legalized pedagogical project imposes strict controls over the work carried out at school, concrete conditions for alternative practices emerge, affirming autonomy not as an abstract universality, but as a concrete and historically constituted autonomy.

The fieldwork was carried out in 37 schools from the São Paulo City municipal network. During 1999 and 2000 the technical teams from these schools - principals, their assistants, and pedagogical coordinators - responded to a questionnaire and participated in four meetings whose purpose was to reflect on the establishment and/or implementation of the pedagogical project at each of those schools.

The information gathered suggest the absence of a public reference for the construction of the ethical horizon indicated in the pedagogical project. The construction and implementation of the pedagogical project at schools reflect much more the search for immediate solutions to the serious problems that affect the school's everyday life. Results also suggest that what is referred to as the school's autonomy turns out to be the autonomy of the school's more active group of educators.
\end{abstract}

\section{Keywords}

Education - Education policy - Political-pedagogical project. 
Neste texto discutimos o projeto pedagógico e a relação com a gestão autônoma da escola, com base em dados levantados junto a 37 escolas municipais de ensino fundamental na cidade de São Paulo que pertencem à mesma Delegacia Regional de Ensino Municipal (DREM). Durante os anos de 1999 e 2000 a equipe técnica dessas escolas - diretores, assistentes de diretoria e coordenadores pedagógicos - respondeu a um questionário e participou de quatro encontros, cujo objetivo foi refletir sobre a implantação e/ou implementação do projeto pedagógico nas respectivas escolas. As análises que se seguem têm como base as respostas ao questionário; ${ }^{1}$ o acompanhamento a duas reuniões de planejamento ocorridas na DREM no início do ano de 1999, das quais participaram as equipes técnicas de todas as escolas; o registro escrito da participação das equipes técnicas das escolas nos quatro encontros; visitas a uma das escolas participantes; análise do seu projeto pedagógico; participação em duas reuniões pedagógicas com os professores, bem como uma entrevista com o diretor e duas com a coordenadora pedagógica dessa escola.

Os encontros tiveram como objetivos a discussão sobre a concepção de projeto pedagógico e como se encontrava a sua concretização nas unidades escolares até aquele momento.

0 fato de participarem dos encontros três ou quatro representantes de cada uma das escolas permitiu que se apreendessem diferentes posicionamentos acerca do projeto pedagógico. Ainda que não tenha havido um acompanhamento mais sistemático da rotina nas escolas, as visitas a uma delas contribuíram para apreensão da dinâmica escolar, das dificuldades que os gestores relatavam nos encontros para a concretização dos planos de ação e o maior ou menor envolvimento dos professores, pais e alunos. As respostas da equipe técnica aos questionários, os encontros, as entrevistas e visitas permitiram reconhecer os limites e possibilidades da autonomia delegada às unidades escolares.
Neste texto analisaremos a autonomia da unidade escolar considerando-a na sua relação com o projeto pedagógico, como prática social. Não se trata de verificar em que medida a autonomia nas escolas distancia-se ou aproxima-se de um nível previamente idealizado ou requerido, mas de compreendê-la num processo dialético, na relação com os processos sociais mais amplos. Como afirma Mészáros (1993, p.138), trata-se de

(...) se apoderar do imediatamente rico "processo de vida ativo" (...) dentro de uma bem definida estrutura teórica orientada pela práxis com a finalidade de elaborar a grande variedade de fatores envolvidos no exame da atividade prática de homens, desenvolvidos historicamente de acordo com determinadas "premissas materiais" e, desse modo, reconstituindo de maneira dialeticamente ativa a própria estrutura teórica (...) [assim] "a questão toda pode ser retratada na sua totalidade".

\section{O projeto pedagógico nas escolas}

Do total das 37 escolas que responderam ao diagnóstico, apenas quatro delas consideraram, na ocasião, que ainda não tinham o projeto pedagógico, pois estava em fase de elaboração. Esses números não se justificam apenas pelo fato de a equipe técnica ser obrigada a cumprir a legislação, mas porque esses educadores tinham uma trajetória de discussão sobre o tema na rede municipal, encontrando-se, no momento da pesquisa, na fase de implantação efetiva dos projetos. Havia unanimidade em reconhecer a importância e a necessidade de a unidade escolar ter um projeto pedagógico. A princípio, as opiniões em torno do tema pareciam ser mais convergentes do que divergentes.

1. No total foram respondidos 115 questionários, distribuídos da seguinte forma: 30 diretores, 27 assistentes de diretores e 58 coordenadores pedagógicos. 
Inicialmente, as respostas ao questionário sugeriam que a equipe técnica (40\%) tomava o projeto pedagógico não como processo mas como resultado, privilegiando-o como instrumento de melhoria dos indicadores de eficiência e eficácia da unidade escolar, do cumprimento da legislação e dos prazos exigidos em vez de valorizar o processo, ou seja, o projeto pedagógico como elemento facilitador da reflexão contínua e sistematizada sobre a escola. ${ }^{2}$

Nas respostas os educadores relacionavam o projeto pedagógico com a possibilidade de a unidade escolar voltar-se para os mesmos objetivos, que passariam a orientar as ações, integrando disciplinas, promovendo a participação, o comprometimento dos educadores e o envolvimento da comunidade.

Tais respostas sugeriam que a equipe técnica tinha, na sua concepção de projeto pedagógico, os mesmos pressupostos dos programas de qualidade total que procuraram trazer para a educação os critérios que orientavam a gestão das empresas. ${ }^{3}$ Vale ressaltar que na gestão anterior, a Secretaria Municipal de Educação (SME) havia desenvolvido na rede um programa orientado por estes princípios, o Programa de Melhoria do Desempenho da Rede Municipal de Ensino de São Paulo (PMDR).

Apenas 4\% das respostas contemplavam a perspectiva de movimento e mudança, fazendo referência ao desenvolvimento de projetos seqüenciais e à avaliação constante como subsídio às novas ações. Nas respostas, a equipe técnica referiu-se aos itens contidos no comunicado 703/97 divulgado pela SME, que orientava a rede para a elaboração do projeto da escola. Neste roteiro a SME indicava detalhadamente o que deveria compor o projeto pedagógico, referindo-se aos objetivos, diagnóstico e caracterização da unidade escolar, às propostas de plano de ação para o conselho de escola, para a associação de pais e mestres, para estimular a participação da comunidade além daquelas ações relacionadas ao desenvolvimento curricular.
Entre os meses de abril e maio de 1997 a Diretoria de Normas Técnicas (DOT) da SME promoveu uma série de reuniões junto aos supervisores, diretores e coordenadores pedagógicos da rede municipal, que resultou no comunicado 703/97, que orientava a construção do projeto da escola segundo as diretrizes da SME: consolidar uma escola de qualidade com base "na valorização do trabalho coletivo, bem como no fortalecimento da autonomia das escolas". ${ }^{4}$ Desta forma a SME relacionava a implantação do projeto pedagógico à autonomia da escola, de acordo com o que preconiza a Lei de Diretrizes e Bases 9394/96. ${ }^{5}$

Durante os encontros, as diferentes concepções de projeto pedagógico foram se evidenciando. Ao contrário do que sugeriam as respostas escritas, poucos educadores reafirmavam a concepção de projeto pedagógico como resultado, a maioria o concebia como processo. Os primeiros tinham nas metas e objetivos estabelecidos um verdadeiro instrumento de controle do trabalho, que lhes permitia identificar, por exemplo, os educadores mais ou menos envolvidos, participativos, etc.

Mas a maioria referia-se ao projeto político-pedagógico da escola, indicando com esse conceito a posição diferenciada que assumiam diante das orientações da SME - comunicado 703/97 -, já que identificavam nelas os mesmos pressupostos contidos no Programa de Melhoria do Desempenho da Rede Municipal de Ensino de São Paulo (PMDR), ao qual se opunham.

Ao optar pelo conceito de projeto político-pedagógico esses educadores procuravam superar o modelo racionalista que caracterizou

\footnotetext{
2. Estes dados iniciais assemelhavam-se àqueles obtidos por Russo (1995) em uma escola estadual na cidade de São Paulo. Com base em observações do cotidiano escolar, 0 autor pode constatar o planejamento escolar como prática burocratizada na qual se privilegia o produto e não 0 processo.

3. Refiro-me especialmente aos programas de Qualidade Total que orientaram a reforma educacional, no estado de Minas Gerais, em meados da década passada (1990).

4. SME/Departamento de Orientações Técnicas (DOT). Projeto da Escola. 1997. Apresentação.

5. Fazendo referência especialmente aos artigos 12, 13, 14 e 15.
} 
o PMDR, ${ }^{6}$ assumindo uma conceituação semelhante àquela apontada por Romão (1997, p. 123) ao referir-se ao Projeto da Escola Básica Cidadã do Instituto Paulo Freire (IPF):

Tentando responder à questão do que deve ser entendido como projeto político-pedagógico, o Projeto [do IPF] propõe a superação do modelo racionalista, que o considera como um pacote de objetivos, metas, procedimentos, programas e atividades aprioristicamente determinados (...) ainda que referenciados numa teoria eleita como a mais adequada. $(1997$, p.123)

Paulo Freire é a principal referência para esses educadores, para quem o projeto político-pedagógico indica o resultado momentâneo de um processo que envolve a ação e reflexão coletiva na escola e que está, portanto, em constante construção:

(...) o projeto político-pedagógico da escola é um processo, um caminhar no cotidiano escolar inserido na realidade mais ampla que o tem como elemento constitutivo, a partir da socialização da discussão crítica de sua história, de sua singularidade, de suas realizações e fracassos, de suas potencialidades e dificuldades. Em resumo, o projeto político-pedagógico da escola é o processo instituinte permanente de uma nova instituição dentro do instituído (...) "0 importante não é chegar a um plano acabado, mas é o processo constante de planejar...” (PEC, p. 46). E, nesse permanente planejar coletivo, as teorias, as concepções de escola, de espaço e de tempo escolares, de currículos, de relações intra e extra-classes, do instituído enfim, são temas recorrentes do processo instituinte. Em outras palavras, ao invés de o projeto político-pedagógico da escola se constituir numa estrutura, ele é antes um processo de estruturação: a partir do instituído, ele é um instrumento instituinte por excelência; ou do ventre do velho existente nasce o novo possível, como dizia Karl Marx. (Romão, 1997, p. 123-124)

A posição aparentemente ambígua das equipes técnicas - nas respostas ao questionário indicando o projeto pedagógico como resultado e nos depoimentos durante os encontros, como processo - evidenciava a trajetória destes profissionais, que se dava, principalmente, no trabalho cotidiano nas escolas e na formação propiciada pela SME. A resposta escrita correspondia formalmente ao sugerido pelo comunicado 703/97 e o relato correspondia à concepção atual de uma parte do grupo sobre o projeto pedagógico.

Inicialmente, a determinação de que todas as escolas elaborem o seu projeto pedagógico (LDB) e a sugestão da SME de como elaborá-lo (comunicado 703/97), com base numa relação estática entre meios e fins, sugerem o aprofundamento da alienação pela instituição de novas formas de exercer o controle e a direção sobre o trabalho dos educadores. No entanto, os educadores, ao assumirem o projeto político-pedagógico com base na consciência prática, indicam as possibilidades presentes neste processo:

(...) a consciência prática (não abstrata) do homem como um ser humano "automediador” que sugere não só a negação da alienação, mas ao contrário a afirmação é positividade que se dá na elaboração de uma posição diferenciada não abstrata mais prática. (Meszaros,1993, p. 164)

Ao falar sobre estes diferentes posicionamentos, durante os encontros, os educadores puderam evidenciar a forte tensão

6. É necessário informar que em 1998 alguns componentes da equipe técnica participaram de palestras sobre o projeto pedagógico em outra delegacia regional de ensino, nas quais já se veiculava a outra concepção de projeto político-pedagógico. Um dos textos de referência nesta formação foi o de Elydio dos Santos Neto. 0 projeto políticopedagógico da escola: caminho para organização e articulação do trabalho coletivo. mimeo. s/d. 
que se estabelece no seu cotidiano, como foi possível perceber também durante as visitas a uma das escolas. Como prática social, a autonomia é ao mesmo tempo positividade e negatividade que se manifestam contraditoriamente nas diferenciadas práticas cotidianas nas escolas. Em seguida, relataremos estas diferentes manifestações.

\section{O projeto pedagógico e a autonomia da unidade escolar}

A normatização/legalização do projeto pedagógico impõe uma série de controles burocratizados ao mesmo tempo em que, na unidade escolar, é exigida da equipe técnica resposta imediata aos mais variados problemas, desde aqueles que refletem as graves condições sociais e econômicas em que se encontram os alunos, os conflitos na unidade escolar, a falta de recursos financeiros para desenvolver os planos de ação e até aqueles relacionados à manutenção do prédio. Os projetos pedagógicos das escolas, em certa medida, refletem a busca de soluções a esses problemas que afetam a todos na unidade escolar. ${ }^{7}$

Como prática social o projeto pedagógico e a autonomia traduzem as históricas contradições das relações sociais nas quais ocorrem. Os educadores encontram-se diante do desafio de gerenciar a equipe e os recursos com o objetivo de construir, com base na autonomia delegada formalmente, uma escola de qualidade, num contexto de mudança em que a forma escolar emerge como forma dominante de educação. Como apontam Saviani (1994) e Mészáros (1993), a importância da escola historicamente hipertrofia-se, pois os processos educativos são estratégicos para a recomposição do poder de controle do capital sobre o trabalho, retransferindo para o corpo social como um todo a medida da expansão e concentração do capital. Na atual fase de acumulação capitalista a escola é fundamental para que se processe "uma transformação cultural, uma universalização consensual de determina- dos valores e instituições humanas" (Coraggio, 1993, p. 21) capazes de tornar mais tolerável a crescente violência que caracteriza o cotidiano, num mundo marcado pelo desemprego estrutural e pelo abandono do cidadão por parte do Estado, o que amplia as possibilidades de desagregação social.

Este cenário nos remete ao roteiro já indicado por Gramsci (1991) quando, no início do século passado, identificava a transformação das condições de vida sob o taylorismo e fordismo. Mészáros (1981, p. 270) afirma que a crise da escola se refere à crise estrutural de todo o sistema da "interiorização" capitalista. À medida que ocorrem as crises econômicas, e se complexifica o sistema de produção da vida material, reajustam-se os mecanismos de "interiorização":

Essa “interiorização”, desnecessário dizer, não pode ocorrer sem o efeito combinado de várias formas de falsa consciência, que representam as relações sociais alienadas de produção de mercadorias como a expressão direta, "natural", dos objetivos e desejos do indivíduo.

Esta intencionalidade se faz presente nas politicas educacionais em vigor, tanto no Brasil como em outros países (C.f. Tommasi, Warde, Haddad, 1996; Catani, 1996; Warde, 1998). O documento da Cepal/Unesco (1992) expressa esta racionalidade que passa a orientar a formação humana sob o domínio da mundialização financeira do capital (Chesnais, 1996).

(...) em face do rígido espírito hierárquico haverá que impulsionar a autonomia individual, a capacidade de inovar, de renovar-

7. Ao justificarem os projetos pedagógicos de suas respectivas escolas as equipes técnicas indicaram inúmeros problemas que pretendiam solucionar. Dentre eles ressaltamos aqueles que se repetem em pelo menos duas escolas: violência, alunos da Febem, problemas de relacionamento entre professores, evasão, alunos/adolescentes indisciplinados, comunidade não participativa, falta de limpeza da escola. 
se, de criar e participar, condições essenciais todas para o exercício da cidadania e para render no mundo do trabalho. (Cepal/ Unesco,1992, p. 119, grifo meu)

0 desafio que se coloca aos sistemas educacionais é o de modificar sua estrutura, deixando a rotina e a rígida hierarquia em favor de um maior dinamismo que permita preparar os indivíduos para que possam "acessar os códigos culturais da modernidade" (Cepal/ Unesco, 1992). Para que se tenha uma escola de qualidade são necessárias a sua transformação e estratégia para isso:

(...) materializa-se num projeto educativo, próprio de cada estabelecimento de ensino, com diferentes níveis possíveis de formalização, e constitui um processo que, segundo uma lógica prospectiva, responde ao incerto e ao imprevisível. Corresponde à produção coletiva de normas e decisões que está no cerne da "construção" pelos atores, de qualquer sistema de ação coletiva, através de um processo coletivo de aprendizagem. (Canário,1995, p. 185, grifos meus)

Desta forma, na última década do século XX, as políticas educacionais recolocam em pauta questões como a autonomia da escola, ${ }^{8}$ associando-a à necessidade de mudança constante e rápida.

Atribui-se à própria unidade escolar, aos profissionais que nela atuam, aos alunos e à comunidade à qual a escola faz parte, via implementação do projeto pedagógico, o poder e a responsabilidade pela transformação. Os resultados são responsabilidade da unidade escolar. Por exemplo, a violência que se manifesta de forma cada vez mais ampla nos grandes centros urbanos, em especial na cidade de São Paulo, se transmuta num problema que pode ser resolvido pela escola, assim como o abismo social e econômico que divide e afasta pessoas segregando-as em classes.
Toda essa propalada transformação das escolas insere-se na reforma dos aparelhos de Estado que têm como ideário as concepções neoliberais que procuram desregulamentar as relações sociais estabelecidas com base no Estado de Bem-Estar Social e instituir mecanismos de regulação pelo mercado. Dito de outra forma, trata-se de desmantelar a politização construída sob as instituições do Welfare State que propiciavam espaços alternativos de controle do fundo público não apenas baseados na acumulação de capital, suprimindo as "alteridades dos sujeitos sócio-econômico-políticos”, privilegiando-se o controle de mercado realizado por representantes do capital, conforme demonstrou Oliveira (1998).

É nesse cenário que a autonomia é delegada às escolas públicas no Brasil. Responsabilizam-se individualmente cada unidade escolar e os profissionais que nela atuam pela inclusão ainda que apenas formal dos excluídos. Sob este aspecto, a autonomia como eixo orientador de políticas educacionais se constitui em instrumento essencial para a efetivação da racionalidade requerida na atual fase de acumulação do capital.

A autonomia delegada reafirma os pressupostos do contrato social retomando e atualizando aquilo que caracteriza a vertente liberal clássica segundo a qual a "estruturação do Estado se dá na passagem do estado de natureza para o estado civil, mediatizada pelo pacto ou contrato social” (Romão, 2000, p. 204). No entanto, o contrato, acordo entre vontades livres independentes e autônomas, se aplica a indivíduos

(...) que da liberdade, conhecem, sobretudo, a falta de vínculos e, da autonomia, a ausência de suportes. Na estrutura do contrato, não existe realmente nenhuma referência a um coletivo, exceto àquele que os contratantes formam entre si. (Castel,1998, p. 598-599)

8. Para uma análise da história relação entre descentralização, gestão democrática e a autonomia escolar ver por exemplo Kraxczyk (1999); Romão (2000); Girardi (1994) e Silva (1994). 
A escola de qualidade resultaria, então, do frágil ajuste que se estabelece entre vontades privadas e autônomas (dos indivíduos ou da instituição e a comunidade próxima) no exercício de um direito inalienável baseado na propriedade privada, fruto do trabalho individual. Contraditoriamente, este frágil ajuste representaria a possibilidade de autodeterminação numa sociedade heterônoma, que se constitui com base no trabalho alienado. Historicamente a autonomia delegada às unidades escolares e prevista nas diretrizes da SME se traduz, então, em mera universalidade abstrata, em ideologia. De fato, apesar da anunciada autonomia legal, a SME mantém rígido controle burocrático sobre as escolas, inclusive como sugere o comunicado 703/97 que orienta a elaboração dos projetos das escolas. Nesse contexto a autonomia, imposta externamente, surge como o canto da sereia, como possibilidade de realização humana, promessa até então não cumprida:

Nenhuma instituição formalizada pode realizar o ideal do homem cuja "realização existe como uma necessidade interna”, porque isso implicaria a contradição de tornar exterior ao homem a sua própria realização. Essa tarefa para ser auto-realização de fato, não poder ser, evidentemente, externa: só pode ser interna. Essa tarefa não pode ser executada para o homem senão pelo próprio homem. A moral é uma função positiva da sociedade: o homem lutando com a tarefa de sua própria realização. A moral, portanto, só não é externa ao homem se, e na medida em que, ela se relaciona com esta tarefa; mas imediatamente se torna externa ao homem quando se abstrai dela. (Mészáros, 1981, p. 169)

Mas é por meio do trabalho nas unidades escolares que os educadores, na escola, se deparam com os limites concretos à autonomia anunciada, o que permite que reconheçam o aspecto conservador da modernização propos- ta. Como afirma Mészáros (1993, p. 18):

(...) enquanto as contradições do mundo social se fortalecem mais do que nunca e se manifestam cada vez mais de um modo que se aproxima de uma escala global avassaladora, declaram-nas, repetidamente, como já “abandonadas” - ou prestes a serem "suprimidas" - numa sucessão interminável de construtos ideológicos que, sob um novo "pós"-rótulo dissocializado, metamorfoseiam verbalmente a mesma racionalização pacificadora, tão logo sua versão anterior tenha perdido sua credibilidade.

É justamente nesta contradição que reside a possibilidade de construção de alternativas a esta lógica que se pretende implantar. Inicialmente os depoimentos permitem afirmar que essa pretensão racionalizadora se desfaz no cotidiano. 0 projeto pedagógico, ainda que normatizado pelos sistemas educacionais com base na própria LDB, pode suscitar transgressões inovadoras. ${ }^{9}$

Os limites financeiros, materiais, humanos e burocráticos impostos pelos gestores municipais, que dificultam a realização dos inúmeros planos de ação criados nesse processo, podem se constituir num momento efetivo de autonomia daqueles que atuam na unidade escolar, orientada pelo "horizonte" indicado no projeto daquele grupo.

Ao mesmo tempo em que o projeto pedagógico normatizado/legalizado impõe sérios controles ao trabalho da equipe técnica e dos outros profissionais que atuam na escola, concretizam-se as condições, pela ausência do principal agente de implantação da racionalidade acima citada - a SME - para as práticas alternativas, que afirmam a autonomia, não como universalidade abstrata mas concreta,

9. Refiro-me aqui a discussão que Arroyo (2000) faz sobre a "inovação legalista" que continua impedindo a livre expressão de formas de gestão coletivamente construídas. 
historicamente constituída.

Assim, os atores, na escola, respondem às inevitáveis exigências burocráticas da SME preenchendo relatórios, enviando informações e cumprindo prazos, horários e datas, mas isto não significa adaptação à norma legal. A autonomia da escola pode se constituir assim, na tensão com estes limites organizacionais, mediada pelo contexto social, político e cultural no qual a escola esta inserida.

Como indiquei anteriormente o Projeto Pedagógico se desdobra em inúmeros planos de ação. ${ }^{10}$ Foi com base nos planos de ação desenvolvidos pelas escolas que procuramos investigar a autonomia como prática social, ou seja, como atividade humana, trabalho ontologicamente fundamental e histórico. Essa perspectiva

Torna-se não só a chave do entendimento das determinações inerentes a todas as formas de alienação, mas também o centro de referência da estratégia prática que visa à superação real da alienação capitalista. (Mészáros, 1981, p. 83)

Como afirma ainda Mészáros (1981, p.155), “a "superação" da alienação tem de ser vista em termos de realidade social prática, isto é, como uma transcendência da alienação na prática social, e não na simples imaginação".

Nesse sentido, algumas ações que se desenvolvem nas escolas indicam um devir, ou seja, alternativas à autonomia delegada, já que são referenciadas em pressupostos diferentes.

A análise dos planos de ação das 37 escolas indica que alguma autonomia se estabelece, com base no trabalho dos atores envolvidos, diante das contradições, limites e conflitos que se estabelecem no cotidiano escolar.

De que modo esta autonomia delegada contribui para que se mantenham e paralelamente se modifiquem práticas estabelecidas e espaços constituídos? Como prática social a autonomia é ao mesmo tempo negada e afirmada. As respostas ao questionário, os depoimen- tos sobre o projeto pedagógico e o desenvolvimento dos planos de ação e as visitas a uma das escolas permitiram identificar a autonomia, relacionada ao projeto pedagógico, na sua negatividade e positividade.

Os projetos pedagógicos de cada escola se desdobram em inúmeros planos de ação que traduzem a dimensão que os educadores dão aos problemas com os quais se deparam no cotidiano escolar. Foi com base nesses planos de ação que percebemos a possibilidade da mudança ou a manutenção do já existente.

\section{A autonomia como prática social nas escolas pesquisadas}

Algumas das escolas pesquisadas ${ }^{11}$ desenvolvem ações que extrapolam a sala de aula. Elas têm-se transformado em verdadeiras "agências culturais", porque o seu espaço físico abre-se a diferentes manifestações culturais - música, teatro, esportes -, organizadas pelos próprios professores e alunos, com o incentivo da equipe técnica, em especial dos diretores, que vêem nelas uma forma de promover a participação da comunidade na escola. Geralmente essas escolas contam com o trabalho constante e continuado ao longo dos anos de um professor ou de um grupo de professores em alguma modalidade cultural ou esportiva. Com o tempo, os eventos que promovem teatro, música e realização de olimpíadas passam a ser referência para a população do bairro.

Esses casos, embora isolados, sugerem a possibilidade do novo. A qualidade da educação nessas escolas se traduz, de acordo com os depoimentos das equipes técnicas, no fato de a escola se constituir em um espaço de convivência democrática.

No entanto este é um aspecto altamente polêmico entre os educadores, como foi possível verificar em uma das visitas à Escola

10. Ao todo enumeramos 115 planos de ação.

11. Apenas três das 37 escolas. 
mais detalhadamente estudada. Lá se desenvolve o projeto Teatro e Produção de Texto para os Alunos do Noturno, coordenado por uma professora de Língua Portuguesa. Parte dos educadores criticava veementemente o fato de a escola desenvolver uma ação voltada para o teatro. Discutia-se a relevância deste projeto diante do fato de as crianças chegarem à $6^{a}$ série do ensino fundamental sem que tenham adquirido, ainda que minimamente, a capacidade de ler e escrever. Para esses professores a escola deixava de cumprir a sua principal função, contribuindo ainda mais para a exclusão desses alunos.

Para os docentes que criticavam a iniciativa, em vez de se diluir os poucos recursos financeiros e o tempo de trabalho dos docentes em muitos planos de ação diferenciados, a escola deveria ter como prioridade garantir que todos os alunos realmente aprendessem a leitura e escrita, condição mínima necessária para sua inclusão. Para os docentes que apoiavam a iniciativa não havia esta incompatibilidade. 0 grupo permaneceu dividido e, vale ressaltar, não buscou resolver o problema com base no consenso. Encaminhou como proposta o atendimento paralelo aos alunos que necessitassem no Projeto Sala de Leitura, que ocorre no espaço físico da biblioteca. Embora o objetivo do Projeto Sala de Leitura não seja o de atendimento paralelo a esses alunos, foi a forma encontrada pelo grupo para procurar corrigir esse problema, considerando a disponibilidade de alguns poucos professores já envolvidos no projeto.

Durante a discussão que se estabeleceu, evidenciou-se um dos problemas mais referidos pelas equipes técnicas nos encontros que é a falta de disponibilidade dos professores para participarem e se envolverem nos planos de ação. Nesta escola poucos professores das séries finais do ensino fundamental tinham a jornada integral. $\mathrm{Ou}$ seja, além dos limites financeiros e materiais, a forma de contratação de pessoal da SME impõe também limites humanos.
A "invenção" de espaços e soluções alternativas aos limites organizacionais, financeiros, humanos e físicos impostos pela SME, parece ser uma constante nas escolas, conforme sugerem os depoimentos das equipes técnicas. A diferença, e não o consenso, parece ser a base para a tomada de decisões, permitindo que nas escolas se manifeste a pluralidade de ações e posicionamentos.

Ainda que os projetos pedagógicos se traduzam em diferentes e inúmeras iniciativas, a maioria delas prevê o envolvimento dos professores em sala de aula. Geralmente as escolas planejam as ações com base na escolha de uma temática central - tema gerador - que orienta o planejamento de palestras, seminários, atividades com os pais e a comunidade e o trabalho dos professores nas respectivas disciplinas. A maioria dos professores se envolve com estes temas na própria sala de aula. $\mathrm{Ou}$ seja, de acordo com a temática central, privilegiam determinados conteúdos do programa a serem trabalhados com os alunos. A autonomia da escola se traduz neste aspecto, como autonomia pedagógica construída coletivamente pelo grupo de docentes, na escola.

Considerado apenas na sua relação com o projeto pedagógico, o exercício da autonomia parece potencializar o espaço de formação docente. É importante frisar, a esse respeito, que os planos de ação voltados à formação de professores são bastante citados. Ou seja, os planos que mais se repetiram depois das parcerias (realizadas por oito escolas) foram os de formação de professores, citados por seis escolas. No entanto, o trabalho docente coletivo não ocorre apenas nessas escolas. Praticamente todas as equipes técnicas se referiram a ele, mesmo porque alguns professores fazem a jornada integral, que pode ou não ser aproveitada em trabalho coletivo. De um modo geral, nas escolas pesquisadas, os depoimentos indicam que há a preocupação em prever espaços e tempos para que o grupo coletivamente possa refletir sobre o trabalho a ser desenvolvido em sala, com os alunos. Esta dinâmica sugere a 
constante reconstrução de programas, métodos e práticas de ensino.

Novamente na escola visitada, conforme o depoimento da coordenadora entrevistada, o "tema gerador" não garantiu coesão temática e nem a participação de todos os profissionais. Eles se agruparam muito mais por afinidades pessoais, pelo horário de trabalho e disciplina que lecionam, ou não participaram dos grupos de trabalho. Isto não significa que estes profissionais não orientem o conteúdo de suas disciplinas de acordo com o tema orientador, mas realizam seu trabalho de maneira solitária.

Como foi possivel perceber nos encontros, esse parece ser um problema que se repete nas outras escolas. As equipes técnicas referiram-se a dificuldades no relacionamento entre professores como um dos obstáculos para a realização de trabalho coletivo. Algumas escolas, procurando sensibilizar os docentes, transformaram as dificuldades de relacionamento em planos de ação, numa tentativa aberta de enfrentamento ao problema.

$\mathrm{Na}$ escola visitada, além de o tema gerador não garantir a participação e envolvimento de todos, não garantiu também a linha de discussão nos grupos. Cada grupo de profissionais imprimiu um sentido a essas discussões, relacionados a sua própria condição profissional e a interesses metodológicos. Confirmando o relato de outras equipes técnicas, na escola visitada, o grupo mais constante nas reuniões e na atuação conjunta era o de professores das séries iniciais do ensino fundamental (de $1^{\text {a à }} 4^{\text {a }}$ série). A principal justificativa para esta situação, além dos problemas de relacionamento, é a falta de tempo, já que os professores trabalham em duas ou mais escolas, e a desmotivação que se instala devido às péssimas condições de trabalho. Esses profissionais vivenciaram ao longo dos anos de atuação na rede a descontinuidade administrativa. Desiludiram-se com o "discurso vazio" que pretende preencher práticas inexistentes, principalmente no que se refere à participação e democratização da escola, numa estrutura que, em várias administrações, se mantém extremamente hierarquizada e autoritária. Investiram muitas vezes seus ideais em vão. ${ }^{12}$

Como prática social dos educadores na escola, a autonomia não pode ser compreendida desvinculada do processo social mais amplo. 0 educador tem uma história, ideais e traz consigo determinadas representações do mundo em que vive. Traz representações acerca do trabalho, de si mesmo e do outro, da educação e da escola. Ao longo de sua história profissional e de vida, na relação concreta com o mundo, adquiriu determinados saberes, que hoje informam também sua prática. Nesse sentido cabe verificar até que ponto o trabalho docente se realiza como necessidade interior plena. Isto é, permite que este educador em sua existência individual se realize, ao mesmo tempo, como ser social. 0 fato de o educador referenciar-se, no seu trabalho, ao coletivo de professores da escola garante a realização plenamente humana deste educador?

A concretização desta possibilidade se dá simultaneamente à abolição da "mediação alienada”,

isto é, da mediação de segunda ordem, institucionalizada em termos capitalistas através da liberação do trabalho de sua sujeição reificada ao poder das coisas, à "necessidade externa"; é através do estímulo consciente da "necessidade interior" que o homem tem de ser humanamente ativo e encontrar realização para os poderes que Ihe são inerentes em sua atividade produtiva, bem como no gozo humano dos produtos não alienados de sua atividade. (Mészáros, 1981, p. 85)

Não podemos afirmar que a participação coletiva realiza esta potência, uma vez que o grupo em si mesmo, desprovido de objetivos significativos, pode manter individualizado cada

12. É a síndrome do professor desistente, ou burnout (Codo, 1999). 
participante do grupo, impedindo a realização de sua humanidade. E os professores identificados como não-participantes, "isolados"? Precisam, necessariamente, participar coletivamente para realizar-se na sua humanidade?

Há que se considerar para esta análise os limites impostos por uma sociedade massificada, tecnificada, informada pelo efêmero, pela imagem, pelos mecanismos da propaganda e do marketing e também pelas ideologias educacionais que ampliam as possibilidades de controle dos seres humanos, na sua subjetividade (cf. Adorno e Horkheimer, 1985; Jameson 1997), e que podem dificultar a percepção da relação entre o trabalho realizado na escola e a autonomia que se delega com a organização social ampla.

A este respeito convém ressaltar que é significativo o número de escolas que desenvolvem ações com o objetivo explícito de estimular determinados sentimentos e emoções em detrimento de outros, como resposta até mesmo à violência que pode permear as relações na escola. Tais projetos são voltados tanto para os alunos como para os professores. ${ }^{13}$ Embora inicialmente este não tenha se constituído em objetivo desta pesquisa, esta é uma das questões que a investigação suscitou e que para ser bem compreendida exigiria um acompanhamento mais próximo do cotidiano escolar. Trata-se de investigar se o trabalho do educador na escola permite a ele a consciência de apenas alguns aspectos isolados das contradições ou permite compreendê-las

(...) em suas inter-relações, isto é, como traços necessários do sistema global do capitalismo. A primeira permanece emaranhada em conflitos locais, mesmo quando a escala da operação é relativamente grande, enquanto a última, ao focalizar sua atenção sobre o tema estrategicamente central do controle social, preocupa-se com uma solução abrangente, mesmo quando seus objetivos imediatos parecem limitados. (Mészáros, 1993, p. 118)

Os dados obtidos nesta pesquisa não nos permitem uma análise aprofundada sobre esse aspecto, que nos remete à contradição fundamental apontada por Mészáros (1993, p. 118, grifo meu):

(...) aqui nos deparamos com o surgimento de uma contradição fundamental: entre a perda efetiva de controle e a forma vigente do mesmo, pois o capital, por sua própria natureza, não pode ser nada a não ser controle, uma vez que é constituído pela objetivação alienada da função do controle como um corpo reificado separado e em oposição ao corpo social em si. Não é surpreendente, portanto, que nos últimos anos, a idéia de controle por parte dos trabalhadores tenha ganhado importância em muitas partes do mundo.

Dito de outra forma, trata-se de verificar até que ponto a autonomia delegada, ou seja, o espaço para que a escola assuma o controle, efetivamente contribui para aprofundar a desumanização e a alienação num contexto em que o capital pode prescindir do discurso da igualdade que caracterizou a revolução burguesa, assumindo, ao contrário, o discurso da diferença.

É significativo que os depoimentos das equipes técnicas sugiram a ausência de uma política pública referendada numa discussão pública sobre as diretrizes da educação no município de São Paulo, apesar da referência legal aos fins e objetivos da educação, conforme o roteiro sugerido pelo comunicado 703/ 97.

A escola na sua singularidade, os processos educacionais, os sujeitos que nela atuam e a construção do projeto pedagógico são referenciados a uma processualidade social ampla. Embora os dados obtidos com a

13. loga (em duas escolas - para professor - propiciar o equilíbrio e calma); Campanhas pela Paz; Inteligência emocional (em duas escolas um deles pretende desenvolver a auto-estima e 0 outro melhorar o relacionamento entre professores); Neurolingüística (para professor - também pretende desenvolver a auto-estima) e Viva a diferença (para os alunos - com o objetivo de estimular a tolerância entre eles). 
pesquisa não nos permitam uma análise da relação entre a autonomia delegada e a formação daqueles que atuam nas escolas, considerando a sua subjetividade, permitiram identificar a ausência de um referencial público para a construção do horizonte ético indicado pelo projeto pedagógico. Ou seja, como já afirmamos anteriormente, nos projetos pedagógicos prevalece a dimensão que os educadores dão aos problemas com os quais se deparam no cotidiano escolar. Embora esses problemas reflitam, em certa medida, as contradições da sociedade na qual as escolas estão inseridas, não garantem, necessariamente, que os projetos estejam referendados por um sentido público para a escola e a educação. A tradução desses problemas em projetos pedagógicos parece representar muito mais a resposta imediata aos problemas que podem impedir o funcionamento da unidade escolar.

A participação da comunidade, especialmente dos pais, é um exemplo disso. É considerada pelos educadores como algo necessário, por representar um indicador de relações democráticas na escola, e principalmente porque os educadores querem os pais como parceiros na manutenção da disciplina e no acompanhamento do processo de aprendizagem dos alunos, assim como pelas contribuições financeiras que fazem via Associação de Pais e Mestres (APM).

Os educadores relatam as inúmeras estratégias de que se utilizam para aproximar os pais da escola. No entanto, os depoimentos indicam que essa aproximação não existe ou existe de modo instrumentalizado. Aqueles que consideram que esta participação existe referem-se:

- ao interesse e o acompanhamento dos pais no desempenho escolar do filho e a sua maior atuação junto à escola;

- ao comparecimento a festas, comemorações e reuniões;

- à prestação de serviços voluntários por parte de alguns pais que apóiam e colabo- ram para a implementação de planos de ação. Os educadores relataram o caso de pais que atuam como inspetores de alunos, auxiliando na manutenção da disciplina, fazendo palestras quando convidados, oferecendo-se para ministrar cursos de artesanato, ou colaborando financeiramente com a APM.

Além dessa participação dos pais, as escolas têm estabelecido parcerias e convênios como forma de suprir a ausência do órgão central, a SME, como provedora de recursos. A autonomia da escola se traduz, aqui, em autonomia para buscar esses recursos na comunidade, o que efetivamente tem ocorrido. Dentre os planos de ação enumerados pelas equipes técnicas das escolas, pelo menos oito referem-se a parcerias: quatro escolas mantêm convênios com universidades que prevêem a assessoria de profissionais especializados em questões como a da violência ou a existência de gangues na escola, podendo também atender diretamente aos alunos; uma escola estabeleceu convênio com escola de idiomas para o ensino de francês aos alunos; duas escolas estabeleceram parcerias com supermercados próximos (um deles subsidia o pagamento de uma psicóloga que atua junto aos alunos e o outro contribui financeiramente, sem se vincular a um projeto específico; e, finalmente, uma outra escola tem parceria com um banco, que contribui financeiramente.

Vale ressaltar que embora o estímulo à participação dos pais e dos parceiros na gestão da escola possa significar, em tese, a própria negação da autonomia da escola, que passaria a ser controlada por esses parceiros e pela comunidade, efetivamente isto não tem ocorrido. Ao contrário, tais iniciativas parecem reafirmar a autonomia dos educadores que atuam na unidade escolar.

Dito de outra forma, parece que aquilo que se chama de autonomia da escola se constitui, no caso das escolas pesquisadas, na autonomia que parte do grupo de educadores 
- equipe técnica e professores - idealizam e constroem na unidade escolar. Novamente há que se perguntar quanto ao horizonte que informa o exercício da autonomia desses educadores. Ou seja, até que ponto a ação desses docentes é informada por interesses corporativos ou por uma cultura pública na qual o público se sobrepõe ao privado. Conforme afirma Arroyo (2000, p. 224), “em vez de falar tanto em autonomia da escola, o que é mais urgente é pensar em afirmar uma cultura pública".

Caberia aqui a análise mais detalhada das relações e conflitos na escola para que pudéssemos indicar em que medida essa autonomia se constrói corporativamente ou não, mas esse não se constituiu em objetivo desta pesquisa. No entanto, como afirmamos acima, não há referência a uma política pública referendada numa discussão pública na construção dos projetos pedagógicos. Sobre isso vale ressaltar que apenas uma escola incluiu no seu projeto pedagógico a participação dos fun-cionários, pois havia lá problemas com o atendimento aos pais, alunos e comunidade. A equipe técnica considerava que se estes funcionários não estivessem integrados nos aspectos pedagógicos, discutidos e considerados normalmente pelos educadores, não poderiam, efetivamente, prestar melhores serviços à comunidade. Quanto aos alunos, apenas três planos de ação os concebiam como agentes principais e não como receptores de serviços prestados. Em um deles, os alunos se responsabilizavam pela manutenção do espaço físico da escola que, nos finais de semana, abriase aos moradores do bairro. Nos outros, as escolas pretendiam estimular os alunos a assumirem a monitoria.

Os dados da pesquisa realizada nestas 37 escolas da Rede Municipal de Ensino de São Paulo sugerem a necessidade de que a construção e a implementação do projeto pedagógico pelos educadores, alunos e a comunidade não se dêem de forma "autônoma", mas organicamente relacionados às políticas públicas, o que pressupõe a construção de uma direção pública não só da escola mas da administração pública, do Estado e seus órgãos de gestão, considerando que a escola pública está a serviço de todos.

A verdadeira meta é a "riqueza interior", que não é um tipo de contemplação abstrata, mas a autoconfirmação da plenitude da atividade de vida de alguém. Isto é, toda a estrutura da atividade de vida precisa ser transformada - desde o trabalho cotidiano até uma participação real nos mais altos níveis de elaboração de políticas que têm influência na nossa vida - e não simplesmente o potencial da produção material de um país. (Mészáros,1981, p. 160)

Ao mesmo tempo em que a pesquisa permitiu perceber os limites da autonomia da escola, considerando a totalidade dos atores, como ideologia, universalidade abstrata, postulado a priori, também permitiu constatar as possibilidades que se apresentam quando tomamos a autonomia construida por alguns educadores na escola. Permitiu identificar ainda que o exercício desta autonomia fortalece o ideário, alimentado pelos educadores, de ampliação dos espaços de trabalho coletivo nas escolas, embora esbarrem com os limites estruturais e humanos que dificultam a realização desse desejo. 


\section{Referências bibliográficas}

ADORNO, Theodor W.; HORKHEIMER, Max. Dialética do esclarecimento: fragmentos filosóficos. Rio de J aneiro: Zahar, 1985.

ADORNO, Theodor W. Palavras e sinais: modelos críticos, 2. Petrópolis: Vozes, 1995.

ARROYO, Miguel G. Ofício de mestre: imagens e auto-imagens. Petrópolis: Vozes, 2000.

CANÁRIO, Rui. Estabelecimento de ensino: a inovação e a gestão de recursos educativos. In: NÓvOA, António (Coord.). As organizações escolares em análise. Lisboa: Dom Quixote, 1995.

CASTEL, Robert. As metamorfoses da questão social: uma crônica do salário. Petrópolis: Vozes, 1998.

CATANI, Afrânio Mendes (Org.). Universidade na América Latina: tendências e perspectivas. São Paulo: Cortez, 1996.

CEPAL/UNESCO. Educación y conocimiento: eje de la transformación productiva con equidad. Santiago: Chile, 1992.

CHESNAIS, François. A mundialização do capital. São Paulo: Xamã, 1996.

(Coord.). A mundialização financeira: gênese, custos e riscos. São Paulo: Xamã, 1998.

CODO, Wanderley (Coord.). Educação: carinho e trabalho. Petrópolis: Vozes; Brasilia: CNTE: Universidade de Brasília; Laboratório de Psicologia do Trabalho, 1999.

CORAGGIO, J osé Luís. Desarrollo humano, economia popular y educacion: el papel de las ONG latinoamericanas en la iniciativa de educación para todos. Nova York, 1993. Não publicado.

FUSARI, J osé Cerchi. A construção da proposta educacional e do trabalho coletivo na unidade escolar. In: BORGES, Abel $S$. et. al. (Org). A autonomia e a qualidade do ensino na escola pública. São Paulo: FDE, 1995. (Série Idéias, 16) Edição especial.

GIRARDI, Maria Neusa. Autonomia da gestão escolar e as funções educacionais do Estado. 1994. Dissertação (Mestrado) Pontifícia Universidade Católica de São Paulo, São Paulo, 1994.

GRAMSCI, Antonio. Maquiavel, a política e o Estado moderno. 8. ed. Rio de J aneiro: Civilização Brasileira, 1991.

J AMESON, Fredric. O marxismo tardio: adorno ou a persistência da dialética. São Paulo: Editora da UNESP/Boitempo, 1997.

KRAWCZYK, Nora. A gestão escolar: um campo minado... análise das propostas de 11 municípios brasileiros. Educação e Sociedade, Campinas, v.20, n. 67, ago. 1999.

MÉSZÁROS, István. Marx: a teoria da alienação. Tradução Waltensir Dutra. Rio de Janeiro: Zahar, 1981.

Filosofia, ideologia e ciência social: ensaios de negação e afirmação. São Paulo: Ensaio, 1993.

OLIVEIRA, Dalila Andrade. Gestão democrática da educação: desafios contemporâneos. Petrópolis: Vozes, 1997.

OLIVEIRA, Francisco de. Os direitos do antivalor. a economia política da hegemonia imperfeita. Petrópolis: Vozes, 1998.

OYAFUSO, Akiko; MAIA, Eny. Plano escolar. caminho para autonomia. São Paulo: CTE, 1998.

PARO, Vitor Henrique. Administração escolar: introdução crítica. São Paulo: Cortez, 1996.

. Gestão democrática da escola pública. São Paulo: Ática, 1997.

PIMENTA, Selma Garrido. Questões sobre a organização do trabalho na escola. In: BORGES, Abel S. et. al. (Org). A autonomia e a qualidade do ensino na escola pública. São Paulo: FDE, 1995. (Série Idéias, 16) Edição especial.

ROMÃO, J osé Eustáquio. Dialética da diferença: o projeto da escola cidadã frente ao projeto pedagógico neoliberal. São Paulo: Cortez, 2000. 
1997. Tese (Doutorado em Educação). Faculdade de Educação, Universidade de São Paulo, São Paulo, 1997.

RUSSO, Miguel Henrique, Teoria e prática da administração escolar: confluências e divergências. 1995. Tese (Doutorado). Faculdade de Educação, Universidade de São Paulo, São Paulo, 1995.

SAVIANI, Demerval. 0 trabalho como princípio educativo frente às novas tecnologias. In: FERRETTI, Celso et al. (Org.). Tecnologias, trabalho e educação. Rio de J aneiro: Vozes, 1994.

SILVA, Maria Aparecida. Administração dos conflitos sociais: as reformas administrativas e educacionais como respostas às questões emergentes da prática social. (0 caso de Minas Gerais). 1994. Tese (Doutorado em Educação). Faculdade de Educação, UNICAMP, Campinas; 1994.

SILVA J R. J oão dos Reis; SGUISSARDI, Valdemar. Novas faces da educação superior no Brasil: reforma do estado e mudança na educação. Bragança Paulista: Edusf, 1999.

SILVA, J air Militão da. A autonomia da escola pública: a re-humanização da escola. Campinas: Papirus, 1996.

TOMMASI, Lívia de; WARDE, Mirian J orge; HADDAD, Sérgio (Orgs.). O Banco Mundial e as políticas educacionais. São Paulo: Cortez, 1996.

VALE, J osé Mizael Ferreira do. Administração educacional e escolar. In: BORGES, Abel S. et. al. (Org). A autonomia e a qualidade do ensino na escola pública. São Paulo: FDE, 1995. (Série Idéias, 16) Edição especial.

VALERIAN, J ean; DIAS, J osé Augusto. Gestão da escola fundamental: subsídios para a análise e sugestão de aperfeiçoamento. São Paulo: Cortez; Paris: UNESCO; Brasília: MEC, 1993.

WARDE, Miriam J orge (Org.). Novas políticas educacionais: críticas e perspectivas. São Paulo: Programa de Estudos Pósgraduados em Educação, História e Filosofia da Educação da PUC/SP, 1998.

Recebido em 17.02.02

Aprovado em 07.11 .02

Ivanise Monfredini é doutora em Educação pela Pontifícia Universidade Católica de São Paulo. Atualmente leciona no Programa de Estudos Pós-Graduados em Educação do Centro Universitário Nove de Julho (Uninove). 